\title{
EL TEATRO DE LAS INSTITUCIONES PÚBLICAS CONTEMPORÁNEAS
}

\section{ARTÍCULO ORIGINAL}

JUNIOR, Jorge Luiz Machado ${ }^{1}$

ESTEVES, Alejandra Luisa Magalhães ${ }^{2}$

JUNIOR, Jorge Luiz Machado. ESTEVES, Alejandra Luisa Magalhães. El Teatro de las Instituciones Públicas Contemporáneas. Revista Científica Multidisciplinar Núcleo do Conhecimento. Año 05, Ed. 01, Vol. 01, págs. 58-86. Enero de 2020. ISSN: 2448-0959, Enlace de acceso: https://www.nucleodoconhecimento.com.br/administracion-de-empresas/elteatro

\section{RESUMEN}

El derecho y las artes escénicas han estado juntos durante siglos. Las tragedias griegas representaron los casos presentados en los tribunales que demuestran un estrecho vínculo entre los dos. A lo largo de los años, las obras de teatro a menudo reflejan las incoherencias de las decisiones judiciales o leyes aplicadas injustamente o ineficazmente. Las artes escénicas se utilizan para ayudar a la ley de pregrado a experimentar las experiencias de la profesión a través de la simulación de tribunales, monitores donde hay una necesidad de puesta en escena. Sin embargo, se enfatiza que la intención es preparar al estudiante para las diversas situaciones que el estudiante puede pasar por el ejercicio de sus actividades. En este contexto, se observan las instituciones públicas y sus peculiaridades. Estos presentan una imagen desgastada frente a los problemas a los que se enfrenta actualmente, como la

\footnotetext{
${ }^{1}$ Licenciado en Administración Pública 7o y Tecnólogo en Gestión Pública.

${ }^{2}$ Doctor en El Programa de Posgrado en Sociología y Antropología. Máster en Historia Social. Especialización en historia de Africa y negro en Brasil. Graduación en Historia.
} 
corrupción y la ineficiencia gerencial que se abordan más profundamente en la búsqueda de posibles soluciones a la lentitud en la prestación de servicios. Por último, cabe señalar que existe la posibilidad de correlacionar el teatro y las instituciones públicas para dilucidar el papel de sus actores en la gestión de los servicios prestados.

Palabras clave: teatro, institución pública, lentitud.

\section{INTRODUCCIÓN}

Teatro y Derecho van de la mano en sus diversas áreas de actividad. En algunos casos, las artes escénicas pueden ayudar en la ingeniosidad de los estudiantes ante el juez a exponer sus instalaciones.

El término teatro tiene una fundación etimológica théatron griega, que configura el arte donde un actor o un grupo de actores representa una historia para un público en un lugar determinado.

El teatro tiene su origen en la antigua Grecia en el siglo IV a. C. como resultado de las fiestas para alabar al Dios de la alegría y la fertilidad, Dionisio. Las artes escénicas estaban representadas sólo por hombres con grandes máscaras, porque las mujeres no eran consideradas parte de la sociedad. También en Grecia vinieron dos hilos de la comedia teatral y la tragedia.

Hacer un breve paralelismo sobre las organizaciones públicas y las artes escénicas puede referirse a la película "The Time Breakdown" donde el director Santiago Dellape retrata la verdad de las instituciones públicas brasileñas con pocos empleados o con actores de apoyo , conocido como "apones". Aunque no es una obra de teatro, vale la pena subrayar la importancia de la obra por su carácter actual y crítico.

El largometraje tiene lugar en la década de 1980, en Brasilia. La Oficina Pública encargada de registrar invenciones y patentes presenta lentitud en la ejecución de sus servicios, cuando llega una máquina, con un aspecto de reloj puntual que permite un viaje en el tiempo en busca de un mejor uso servicio público, que es visto como negligente y desinteresado. Sin embargo, es necesario señalar que los obstáculos 
burocráticos inherentes al sistema obstaculizan la continuidad del espectáculo. Las trágicas obras de teatro contó con temas relacionados con la justicia y las normas.

De las revoluciones que ocurrieron en Europa en los siglos XVII y XIX y de la erosión de la burguesía, las obras han sufrido influencias desde el momento histórico y presentan un carácter más individual que pierde su naturaleza social.

Las influencias del movimiento romántico trajeron a la pieza el lema de la Revolución Francesa: fraternidad, igualdad y libertad. En el siglo XX, el teatro se convierte en una herramienta de la sociedad para el debate y la crítica, sin gran atención las alegorías de los escenarios y vestuarios, con la intención de aclarar la realidad social.

Según Teixeira (2018) hay pruebas de que los teatros se originaron en la Antigua Grecia a semejanza de los tribunales y también fueron empleados para representar a la organización judicial, permitiendo al pueblo juzgar a sus criminales a través de sus puestas en escena. Aclara a través de las palabras de Jeniffer Wise, profesor de historia teatral en la Universidad de Victoria que ambos reflejan "democracia en acción" y proporcionan una evaluación de las normas jurídicas con las experiencias concretas de la sociedad.

Por lo tanto, el objetivo de este artículo es proponer una reflexión sobre el lector sobre el tema. Las artes escénicas utilizadas desde su origen hasta la actualidad como herramienta de crítica social y sensibilización política, también con el objetivo de intervenir en el Derecho para la elaboración y modificación de leyes para la sociedad y en el desarrollo de servidores que representan los constates cambiantes de las instituciones públicas contemporáneas.

Actualmente, el arte es un lenguaje universal que persiste en presentar los aspectos llamativos de la sociedad. La interpretación promueve el conocimiento de dinámicas innovadoras y diferentes de la vida cotidiana del intérprete. Es imprescindible destacar la articulación entre el teatro y las entidades públicas para identificar y familiarizar conceptos y funciones empleando a la ligera, pero critica la ineficacia que presentan. 


\section{INSTITUCIONES PÚBLICAS}

Las instituciones fueron concebidas, en la antigua ley romana con el plan de realizar la voluntad del fundador, logrando sus objetivos. En el Imperio Romano inferior, a través de la ideología cristiana que predicaba la caridad surgieron los cimientos originales. Al entender la teoría individualista en la visión de Bobbio (1992), los hombres son dueños de los derechos y receptores de estos derechos, en las fundaciones, son aquellos para los que se originó.

En la época medieval, los cimientos actuaban bajo el apoyo de la Iglesia y tenían un carácter público reducido con el origen de las naciones contemporáneas y la relevancia inherente al derecho civil.

El Decreto-ley No 200/67 estableció que las fundaciones eran similares a las empresas públicas e incorporaban la administración pública indirecta. Otros decretos cuestionaron posteriormente el posicionamiento de las entidades públicas como parte de la administración indirecta.

El Decreto-Ley No 2.299/86, añadiendo el párrafo 2, enmarcó las instituciones en la lista de administración indirecta a las generadas, con la intención de sobornarlas a herramientas y directrices para la inspección, control y gestión financiera, además del plan de carrera establecido por la Ley No 5.645/70.com advenimiento de los cambios, a través de la ley, las fundaciones presentaban un carácter jurídico mayoritariamente público porque no adoptan varias leyes civiles. En esta regla, las entidades fueron sometidos al Código Civil sólo en relación con la forma de constitución.

La literalidad constitucional diferenciaba fundaciones públicas y privadas. Con la llegada de la enmienda constitucional No 19/98, ya no empleó la expresión fundación pública los cambios aclaran que la Constitución no distingue, por lo tanto, las normas de la Carta Magna abarcan todo tipo de fundamentos.

Arte. $50 \mathrm{~A}$ los efectos de la presente ley, se considerará que: 
IV - Fundación Pública - la entidad con personalidad jurídica de derecho privado, sin ánimo de lucro, creada en virtud de la autorización legislativa, para el desarrollo de actividades que no requieran ejecución por órganos o entidades de derecho público, con autonomía administrativa, equidad gestionada por los respectivos órganos de dirección y operación financiada con recursos de la Unión y otras fuentes (BRASIL, 1988, p. 13)

Las entidades de derecho público son originarias de la ley, mientras que las de derecho privado se generan mediante autorización legal, como presunciones de derecho civil. Ambos, adquiriendo derechos y obligaciones en su propio nombre. Según el Tribunal Supremo en la Acción Directa de Inconstitucionalidad 191/RS en la que la ponente era Ministra Carmen Lucía. Las formas que se crearon las fundaciones difieren del Público, las fundaciones privadas debido a la propiedad y naturaleza de los servicios prestados (ADMIN, 2008).

En cuanto a las normas de administración, las entidades públicas de administración indirecta cumplen con las normas de administración pública adecuadas a su personalidad, que es pública o privada. (CARVALHO FILHO, 2009).

De esta manera se aclara el Arte. 37 de la Carta Magna:

Arte. 37. La administración pública directa e indirecta de cualquiera de las Potencias de la Unión, los Estados, el Distrito Federal y los municipios cumplirá con los principios de legalidad, impersonalidad, moralidad, publicidad y eficiencia, así como los siguientes:

XIX - Sólo por derecho específico puede crearse la institución de la empresa pública, la economía mixta y la fundación, con la ley complementaria, en este caso, la definición de las áreas de sus operaciones. (BRASIL, 1988, p. 36 -37).

Por lo tanto, las organizaciones públicas pueden estar compuestas por las autoridades públicas con capital, en su totalidad o parcialmente pública, supervisadas por la 
gestión pública, con la posibilidad de autoadministración dentro de los límites de la norma.

Los activos de las organizaciones de derecho público se denominan bien público protegido por todos los privilegios, como la inaplicabilidad de los activos. Los activos de las instituciones de derecho privado no encajan como bienes públicos.

Se dice que los cambios experimentados en el ámbito de la gestión pública en Brasil en la búsqueda de la revitalización de las acciones del Estado, las mejoras en el desempeño de los servicios prestados, así como la génesis de nuevas directrices en la relación con la (MOTTA, 2007). Sin embargo, la implementación de estos cambios se debe al mantenimiento de aspectos clásicos de la administración pública. Como una obra que es largamente expuesta con gran aceptación por parte del público, donde los actores quieren cambiar el guión, improvisar, pero el autor no lo permite.

Anteriormente, el régimen jurídico adoptado por los funcionarios de estas fundaciones sería el mismo, como lo afirma el art. 39 del CF, que estableció el régimen jurídico único. Con la llegada de las CE No 19/98, este sistema fue eliminado y el régimen de personal se convirtió en el utilizado por la persona federativa establecida a través de la legislación. Ambas entidades tienen una responsabilidad objetiva, porque el arte. 37, el artículo 6 de la Constitución se aclara (BRAZIL, 1988).

La cultura organizacional es un elemento relevante para entender el desempeño de las organizaciones, especialmente después de las intervenciones. Esta propuesta busca redefinir las omisiones y acciones del Estado y lograr cambios significativos en la gestión de las entidades públicas, según Silva y Fadul (2010).

La crisis a la que se enfrenta el Estado y la credibilidad de quienes gestionan diversas organizaciones públicas requerían una reconstrucción interna para garantizar la propiedad de los contratos, además de ayudar a la coordinación económica en el mercado y reducir las desigualdades Social. Este plan busca permitir a los gerentes tomar decisiones asertivas y que los servicios, directa o indirectamente subordinados a él, funcionen de manera más efectiva. 
La globalización ha hecho que sea relevante redefinir sus tareas. Anteriormente, la incorporación mundial de mercados y modos productivos, los Estados tenían como uno de sus objetivos básicos salvaguardar sus economías de competencia internacional. Después del proceso de globalización, el Estado no pudo mantener esta postura, sino adoptar un sistema económico interno fuerte que lo haga competitivo internacionalmente.

A estos elementos se suma el gran retroceso social generado por el gobierno neoliberal, ya que nos enfrentamos al Estado postdemócrata, donde todo se convierte en mercancía y las decisiones políticas se toman por la dirección de grandes corporaciones transnacionales, mercados, entre otros. Así, las entidades públicas no ejercen sus funciones de manera integral si no actúan dentro de los límites de los anhelos del neoliberalismo, lo que demuestra su desprecio por los procesos de legitimación popular, así como su profunda implicación con el capital financiero.

La diferencia entre un plan de reforma neoliberal y un plan social democrático está en el objetivo. En la primera, se busca al Estado retirarse de la economía, mientras que en la segunda intención es aumentar la gobernanza del Estado.

Entender la naturaleza de la crisis y la necesidad indispensable de aplicar la reforma en el Estado se produjo de una manera imprevista y controvertida. El país sufrió un período de cristalización del ingreso per cápita de 1979 a 1994 y una inflación profunda.

Lo que causó esta crisis en la economía fue la crisis del Estado, que persiste hasta hoy, a pesar de los esfuerzos para poner fin a ella. La depresión iniciada en 1979 fue generada por la segunda crisis del petróleo, que se identifica por la falta de capacidad estatal para estructurar el sistema económico para integralizar el mercado. Esta crisis se define como una resección de varios frentes: fiscal, político, el método de interferencia del Estado, de la Administración del Estado. Con la llegada del Plan Real en 1994, los precios se estabilizaron favoreciendo la recuperación del crecimiento económico. 
La inestabilidad política presentó tres períodos, según Pereira (1996): una crisis del sistema militar; y una crisis moral, que dio lugar a la descundancia de Collor; la inestabilidad del método de intervención, ampliada por la globalización económica mundial, se clasificó por el debilitamiento del modo proteccionista del intercambio de importaciones, lo que se demostró en ausencia de competitividad de una gran parte de las empresas Mujeres brasileñas; apareció en el fracaso para acercar a Brasil a los modelos socialdemócratas europeos.

La Constitución de 1988 llevó la gestión administrativa al nivel opuesto: una intensa rigidez burocrática. Los resultados son altos costos y menor calidad de la gestión administrativa brasileña.

Esta reforma tenía como objetivo implementar mejores condiciones para la aplicación de las leyes y políticas públicas y hacer más capacitados las actividades exclusivas del Estado, mediante el cambio de municipios en "organismos autónomos", así como modificar los servicios sociales competitivos en organizaciones sociales.

En el Estado no se presentaron nuevas licitaciones públicas, ya que se presentaron cálculos en los que había servidores más inactivos que activos (MOTTA, 2007). Mientras tanto, con recursos humanos reducidos, el Estado estaba a merced de la crisis fiscal. Según (BRASIL, PDRA, 1995, p.26) "La rigidez de la estabilidad garantizada a los funcionarios impide la adecuación del personal a las necesidades reales del servicio, y dificulta la recogida de la obra".

El procedimiento monetario de la Unión se define por la asimetría, porque en Brasil no existe un sistema de remuneración estandarizado. La planificación de la reforma se inspiró en la administración británica y tenía como objetivo fundar un nuevo estándar de gestión pública, basado en la demanda de más rápido con un enfoque en los resultados, el control público y social.

La liquidación fiscal se logrará mediante: la exención de los servidores excedentarias, la delimitación del límite máximo salarial de los empleados y el cambio del proceso de 
jubilación, con el aumento del tiempo de servicio, y la edad mínima de jubilación, con un tiempo mínimo de servicio y valor proporcional a la contribución.

La modernización de la gestión pública se presenta como consecuencia del plan de reforma que buscará fortalecer el centro estratégico del Estado y desorientar la gestión pública a través de la introducción de otros centros controlados por contratos de gestión. Este Plan intenta revitalizar la competencia administrativa central y ofrecer autonomía a los organismos y organizaciones sociales. Para lograr el triunfo con la introducción de la Reforma, es imperativo el compromiso de todos los actores y directores involucrados en todas las áreas dentro de sus prerrogativas específicas.

Vale la pena reflejar cómo esas ideas están siendo aceptadas y empleadas en la rutina de las organizaciones públicas. Como explica Motta (2007), la administración pública está correlacionada con la famosa cultura y tales reformas no pueden interrumpir este vínculo inmediatamente. En este contexto, añade que el patrimonialismo y el personalismo persisten y guían los convenios de preservación de coaliciones de poder y salvaguarda de los objetivos de colectividades preferenciales.

A través de la experiencia conjunta de los equipos de organizaciones son conclusiones de los problemas rutinarios de la empresa, ya que son patrones y opiniones compartidas que establecen el modus operativo. Estos patrones y opiniones compartidas forman la cultura organizacional (MOTTA, VASCONCELOS, 2006).

La premeemencia de producir un concepto positivo se ha convertido en la base principal de las administraciones que buscan alcanzar la calidad. En lugar de aplicar inversiones en la reestructuración del aparato público gubernamental o en proyectos y servicios, se desembolsa una gran cantidad de recursos para encubrir la realidad de la corrupción, el desguace y el nepotismo. La ineficacia los sostiene y los cubre desde el principio de las entidades públicas brasileñas. (SCHAUN, 1986).

Se dice que las actividades intrínsecas del Estado son prerrogativas para legislar y gravar, que abarcan a la policía, las fuerzas militares, las entidades supervisoras y reguladoras, y los organismos encargados de la asignación de recursos. 
Servicios no peculiares, que el Estado ejerce y/o patrocina porque los consideran extremadamente pertinentes para los derechos humanos o abarcan las economías externas.

Por último, en cada sector se debe analizar qué tipo de naturaleza es y qué tipo de gestión pública es la más adecuada.

La complejidad inherente a las instituciones y a la Reforma es un tema que necesita un análisis de varios puntos de la historia del país. No se trata de una simple cuestión administrativa la degradación de las entidades públicas y, para entender este proceso, deben analizarse tres razones, que son: la cultura brasileña; corrupción inherente al gobierno y la incapacidad de gestión del aparato público del gobierno.

\subsection{FACTORES DE DEGRADACIONES DE INSTITUCIONES PUBLICAS}

\section{a. Cultura brasileña}

Nelson Werneck Sodré (1996) revela en su obra "Síntesis de la historia de la cultura brasileña" que los primeros cultos del país fueron los jesuitas. En la enseñanza religiosa las enseñanzas se transmitían con el objetivo esencial de la catequesis. Después de muchos años siguiendo este sistema, la Reforma Pombalina es generada por la necesidad de la proscripción de los jesuitas, lo que no conduce a la elaboración de un nuevo método educativo y beneficia la disminución de la enseñanza en Brasil. Los sacerdotes y capellanes eran los únicos con conocimiento, pero sin fundamento pedagógico. El proceso educativo era para unos pocos y la conclusión se llevó a cabo generalmente en los países europeos.

La cultura, según Sodré (1996), tenía como objetivo lograr el diploma, no el conocimiento, y deliberaba que sus estudiantes serían predicadores, cultos y genios y que, por lo tanto, aspiraban a profesiones liberales y empleos públicos. La cultura de los indios y los negros era constricción y estos no estaban permitidos aprender, un hecho que impedía sus avances. Esta divergencia entre la abstracción política 
avanzada y el retraso del medio ambiente demostró el punto de desorientación cultural inherente a los pueblos con antecedentes coloniales.

La consecuencia de estos hechos fue una escuela primaria mediocre por parte del Estado y una escuela secundaria relegada a organizaciones privadas, que presentaban carácter financiero e intangible a las clases más humildes de la población. A mediados del siglo XXI, Brasil tiene una tasa de analfabetismo del 7\% entre las personas de 15 años o más según datos del IBGE (OLIVEIRA, 2018). Un índice todavía muy alejado de los presentados por los países desarrollados y algunos en desarrollo, como Corea, que en 45 años prácticamente erradicó el analfabetismo y puso al $82 \%$ de los jóvenes a la universidad. (MAZILLI, 2011).

Nelson Sodré (1996) presenta un análisis relevante sobre la interferencia de los medios de comunicación en el proceso educativo de la población:

Nuestro pue[...]blo sigue siendo acusado por el bajo nivel; los exploradores comerciales e ideológicos de los medios de comunicación serían meras víctimas de este gusto popular incorregible; Al final, sólo están proporcionando lo que se les impone n.o las exigencias de este mal gusto. Esta impostura alcanza los límites del escarnio, cuando se sabe que la verdad es muy diferente: el público acepta y busca lo mejor. (SODRÉ, 1996, p.79).

Ante este panorama de ignorancia, parece poco probable que la población brasileña combata las deliberaciones del sistema, sin embargo, las políticas públicas destinadas a contribuir a la entrada de las clases menos favorecidas en la educación superior y los cambios curriculares en la escuela primaria y secundaria tienen como objetivo equilibrar el equilibrio de conocimientopara todos.

Mientras que en otros tiempos, la prensa actuó como la conciencia de la población, ahora la gente cuestiona y se rebela contra la prensa, tal vez por el advenimiento de Internet, pero principalmente al despertar del conocimiento. 


\section{b. Corrupción}

La corrupción ha sido un problema común en todos los medios de comunicación y se presenta como uno de los factores que conducen al deterioro de la reputación de las entidades públicas. Del mismo modo, los estudios sobre el tema se han ido ampliando y, en su mayor parte, lo consideran una cuestión moral. Bezerra (1995), en su obra "Corrupción: un estudio sobre el poder público y las relaciones personales en Brasil" conceptualiza la corrupción como un "fenómeno de naturaleza estructural, arraigado en nuestra formación social, a nuestros hábitos y costumbres".

Las denuncias de corrupción han sido más frecuentes y son retratadas por los medios de comunicación como una crisis ética. Es necesario, para resolver el problema, establecer normas morales más estrictas y éticas (BEZERRA, 1995).

El autor asocia corrupción y relaciones personales y redes. Según él, los lazos de amistad, parentesco o patrocinio son propulsores para justificar actos de corrupción.

Stukart (1988) subrayó este vínculo entre los actos corruptos frente a las relaciones sociales: "Sin duda, los privilegios moralmente apócrifoes y las mayordomías también son un medio de soborno". Bezerra (1995) complementa:

No son por fin hechos excepcionales, sino prácticas rutinarias. Cabe señalar también que una rápida observación de las denuncias de corrupción en los últimos años permite señalar que la conducta así designada no es exclusiva de un período, sino que ha reproducido y cruzado diferentes grupos políticos y gobiernos (BEZERRA, 1995, p. 186).

El autor aclara que la corrupción es parte de la cultura de la población brasileña y que, incluso los opuestos a estas prácticas, cuando alcanzan su estatus, favorecen las relaciones personales.

[...] leemos casi a diario en periódicos y revistas casos de corrupción, pero rara vez leemos sobre la compensación del daño y/o castigo de los 
corruptos, dando la impresión de que sufrimos un síndrome de impunidad, lo que lleva a algunos a concluir que realmente 'el crimen vale la pena. (STUKART, 1988, p.52).

Estos actos están siendo gradualmente más expuestos a la sociedad y contribuyen a la imagen de precariedad de todo el sistema gubernamental. Para cambiar este marco, la actitud de la sociedad en la confrontación contra la corrupción es imprescindible. El esfuerzo social constante y la condena de los corruptores pueden emplear cambios importantes para reducir o incluso erradicar la corrupción en el país (STUKART, 1988).

El autor añade: El código de ética, creado de acuerdo con la necesidad de supervivencia de un grupo necesita sanciones y castigos, por lo que no es sólo un montón de meras palabras vacías. La negligencia en su aplicación determinará su desaparición gradual. (STUKART, 1988).

Según datos recientes del Instituto de Transparencia Internacional, Brasil ocupó el puesto 96 en los países menos corruptos del mundo, cayendo 17 posiciones en comparación con el estudio anterior. La mayoría de los territorios considerados más corruptos viven en un sistema político dictatorial o presentan conflictos religiosos y malas condiciones de vida de la población. (EXAME, 2018)

c. Discapacidad gerenciales

Es importante organizar al Estado para abandonar los sistemas burocráticos del pasado para que pueda establecer métodos de gestión que establezcan en el comportamiento de la obra pública conceptos imperativos de calidad, productividad y responsabilidad empleados, según Pereira y Spink (1998, p. 23-24).

Los ciudadanos exigen mucho más al estado de lo que el estado puede ofrecer. En este caso, la función de una administración pública eficiente se convierte en valor estratégico, reduciendo la brecha que separa la demanda social y la satisfacción de esta demanda. El objetivo es construir un estado que responda a las necesidades de sus ciudadanos; 
estado democrático, en el que es posible que los políticos supervisen el desempeño de los burócratas y están obligados por ley a dar cuenta de ellos, y donde los votantes pueden monitorear el desempeño de los políticos y también están obligados por ley a Cuenta.

Los autores antes mencionados declaran que la crisis burocrática de la gestión pública brasileña se originó en el régimen militar, frente al patrimonialismo que impidió la consolidación de una burocracia profesional que contrató gerentes a través de empresas estatales. La Carta Magna de 1988 menospreció las nuevas directrices de la administración pública.

Los electores y, más ampliamente, la sociedad brasileña, revelaron en este momento una increíble falta de capacidad para ver lo nuevo. Sólo se dieron cuenta de que la administración burocrática clásica, que había comenzado a aplicarse en el país en la década de 1930, no había sido plenamente establecida. Vieron que el Estado había adoptado estrategias descentralizadoras -los municipios y fundaciones públicasque no se ajustaban al modelo burocrático-profesional clásico. Se dieron cuenta de que esta descentralización había abierto espacio para el clientelismo, especialmente en los estados y municipios, clientelismo que había aumentado después de la redemocratización. Sin embargo, no se dieron cuenta de que las formas más descentralizadas y flexibles de la administración, que el Decreto-Ley No 200/1967 había consagrado, eran una respuesta a la necesidad de que el Estado gestionara eficientemente las empresas y los servicios sociales. $\mathrm{Y}$ decidieron completar la revolución burocrática antes de pensar en los principios de la administración pública moderna. Al actuar así, aparentemente siguieron una lógica lineal compatible con la idea de que primero sería necesario completar la revolución mecánica para sólo entonces participar en la revolución electrónica. (PEREIRA e SPINK, 1999, p.246).

Muchos estudiosos de las ciencias políticas definen la importancia de adoptar, por la máquina pública del estado, la eficacia del sector privado y el uso de conceptos como 
la calidad y la agilidad en la prestación de sus servicios. En este contexto, las acciones van desde la privatización de las organizaciones públicas hasta la adopción de un método híbrido de administración, apoyado por Ferlie et al (1999).

Según Ferlie et al (1999), el método híbrido sugerido no es fiable ni lógico, pero podría funcionar observando dos elementos: la recaudación de impuestos y el mercado privado.

Un análisis preparado por el Banco Interamericano de Desarrollo - BID demuestra el tiempo, el dinero y la productividad perdidos frente a la burocracia en los países de América Latina. La falta de inversiones socava el aumento de la velocidad de los servicios públicos. Los procedimientos en línea tardan un $74 \%$ menos que los procedimientos presenciales para completar y generar un menor costo, también digitalizar documentos y disminuir la incidencia de corrupción. "El promedio de un solo procedimiento es de 5,4 horas, pero algunas naciones pueden tener llamadas que tardan más de 11 horas". (BID, 2018, p.4)

Los procedimientos burocráticos son difíciles en la región: son lentos, susceptibles a la corrupción y terminan excluyendo a las personas con menos recursos. Muchos de ellos todavía son cara a cara e implican documentos en papel. Los ciudadanos pierden el tiempo yendo de contador en contra y, en muchos casos, terminan pagando sobornos a los servidores. Las empresas pierden horas productivas y, con ellas, forman parte de su competitividad. El Estado se pierde en medio de procedimientos complejos y manuales y no puede conectar las políticas públicas con los beneficiarios previstos (BID, 2018, p.2 )

El gasto de atención cara a cara cuesta hasta 40 veces más que un servicio computarizado al gobierno. Brasil es uno de los países que emplea tecnologías más innovadoras en el sector público. Lamentablemente, todavía no es suficiente llegar a la Unión Europea, por ejemplo, que dispone del 81 \% de los servicios computarizados. Con respecto a la calidad, en los países latinos está muy por debajo de lo que se espera. Sólo la mitad de los procedimientos se resuelven en una sola interacción con 
el organismo público y el $25 \%$ de ellos requieren tres interacciones o más, lo que genera un gran costo al acceder a servicios básicos como la educación, la salud, el pago de impuestos y la obtención de un Certificado de nacimiento (FERRARI, 2018)

En este contexto, "Brasil requiere en promedio 5,4 horas para resolver procedimientos burocráticos" (BID, 2018. p.4). La ideología antagónica de que el Estado debe operar como una empresa privada en la prestación de servicios son Osborne y Gaebler. Los autores destacan las divergencias entre las instituciones públicas y privadas, lo que está en consonancia con el uso de un único método de administración.

El gobierno es democrático y abierto; por lo que sus movimientos son más lentos en comparación con los de las empresas, cuyos administradores pueden tomar decisiones rápidas a puerta cerrada. La misión fundamental del gobierno es 'hacer el bien', no es 'ganar dinero'. [...]. Estas diferencias conducen a una conclusión: no se puede gobernar como quién dirige una empresa, aunque ciertamente hay muchas similitudes entre las dos actividades. (OSBORNE e GAEBLER, 1994, p.22).

Estos autores afirman que cualquier institución, pública o privada, puede emprender o ser burocrática. En Brasil, las entidades públicas son extremadamente burocráticas, lo que hace que los procedimientos administrativos consuman mucho tiempo, reduce la productividad y aumenta la corrupción (LAH-Z, 2003).

En una encuesta realizada por el Banco Mundial en 133 países sobre la burocracia gubernamental y sus efectos en la economía, aclara que el tiempo es un factor más relevante que los costos. Según Rita Ramalho, directora del Banco Mundial "Perder tiempo con la burocracia le cuesta a Brasil más que impuestos. Una simplificación del sistema tributario actual para facilitar la vida del contribuyente" (LIMA, 2017)

En un ranking de ponderación, Brasil es considerado uno de los más burocráticos, tardando 80 días en el progreso de todo el proceso.

cubre el análisis histórico del estado moderno y argumenta: 
Hay modernización, no se puede negar, pero es una modernización llamada conservadora. Es la que hizo Getúlio Vargas, a la que también hicieron los militares, una modernización que viene de arriba, donde el estado es extremadamente poderoso. En el caso brasileño actual, como en todo el mundo, también, lo que está en juego es este restablecimiento del estado. Es un estado que necesita ser reconstruido paralelo a la construcción sólida de una sociedad. En el caso específico del Brasil, es necesario reconstruir el Estado, pero está claro que necesitamos urgentemente construir una sociedad. No querer ser pesimista, esto no sucederá en un pase de magia, no sucedió ni sucedió en ninguna parte del mundo; y es bueno que no suceda, porque si sucede es un castillo de arena que se va a derrumbar en cualquier momento. Pero es necesario construir esta sociedad, aunque lleva algún tiempo, no importa[...]. (PINHO, 2001p. 37)

Caio Marini (2003) en su obra "Gestión pública: debate contemporáneo" trata de la sostenibilidad en el camino de la modernización administrativa del Estado y aclara:

[...] el debate contemporáneo sob[...]re cuestiones de gestión pública parece reafirmar algunos de los principios básicos de la agenda actual, tales como: enfoque ciudadano, transparencia, control social, conciencia de la responsabilidad fiscal, gestión de los resultados, la ética y la profesionalización del servidor público. El gran reto es garantizar la irreversibilidad del proceso de transformación desde el fortalecimiento de iniciativas exitosas y el realineamiento necesario para la incorporación de temas emergentes. (MARINI, 2003, p.82).

Según Roesler (2017), las organizaciones públicas no están funcionando porque no cumple con las reivindicaciones neoliberales. El Poder Ejecutivo y el Congreso Nacional han estado trabajando juntos para tratar de implementar reformas que favorezcan el Capital Financiero sin prestar atención a los intereses y necesidades de la población. También según el magistrado, las reformas son un revés en varios aspectos y complementos: "El horizonte legislativo es promover más reveses sociales 
a través de "reformas" que socaven la dignidad del ciudadano brasileño". (ROESLER, 2017).

La perspectiva neoliberal determina que todo puede ser privatizado, lo que ha estado sucediendo con varias empresas públicas y el patrimonio del país. Frente al Poder Judicial, el magistrado denuncia la indecisión de los jueces que hoy aplican una "justicia alternativa" en detrimento de la Constitución Federal y el Ministerio Público actúa selectivamente con el pretexto de combatir la corrupción y salvaguardar la seguridad pública (ROESLER, 2017)

Se observa, en resumen, que la degradación de la imagen de las organizaciones públicas no es un problema actual, sino que persiste y aumenta frente a las políticas de beneficios gubernamentales. Esta metodología se ha dado cuenta de una reputación negativa para los gobiernos y los gobiernos. Este escenario perjudica a los hombres serios y honestos que entran en política para cambiar la situación gradualmente. Aquí está la deseducación de la población, que no puede diferenciar la ética de lo poco ético.

\section{EL TEATRO Y LA DERECHA}

Se considera teatro como una especie artística, y el arte como un movimiento autosuficiente, relacionado con el placer y la reflexión. La tragedia, desde el principio de los tiempos, tiene el carácter del ritual cívico como un encuentro social que denotaba la vida pública de los pólis atenienses en el siglo V.

Frente a un análisis selectivo centrado en la comprensión es posible señalar algunos medios de correlación, la experiencia jurídica de los tribunales atenienses. Es necesario recuperar dos categorías: los procesos elaborados y los sujetos insertados en las piezas. Por lo que respecta al procedimiento, existe una analogía entre los medios encontrados para garantizar la ejecución de tragedias y las acciones procesales de los tribunales atenienses. 
Según Roland Barthes (1990), es esencial subrayar drásticamente el carácter civil del teatro griego, sobre todo de la tragedia, ya que fue la ciudad la que le proporcionó su esencia. La descripción de la tragedia como un suplemento de la dinámica de pólis se produce, según Barthes (1990).

Las tragedias fueron todas conmemoraciones para alabar al dios Dionisio y el teatro estaba destinado a la adoración. Para decidir qué grupo presentaría la tragedia en las celebraciones se hizo un concurso, donde la arconera, oficial de los pólis, se encargó de preparar a los actores frente a un grupo de jurados que decidieron, después de la puesta en escena que actuarían en el homenaje.

La coreografía fue un patrocinio atribuido por ciudadanos ricos para montar tragedias. Después de la decisión de la competencia la arconera, designó coregos. Complementos (BARTHES, 1990, p.71) "Los cargos financieros eran pesados: hasta corego alquilar la sala de ensayo, pagar el equipo, proporcionar bebida a los artistas, pagar la remuneración diaria de los artistas".

Teatro fue una especie de apoyo proporcionado por pólis. Las actuaciones fueron originalmente gratuitas, sin embargo, el número de espectadores aumentó gradualmente. En este contexto, dos obolos por día de barthes show (1990) comenzaron a ser cargados. Todos estos procedimientos para elegir, patrocinar y asistir a la pieza representan el control directo de los plyólis a través de sus organizaciones y representantes.

Paralelamente, se verifican algunas conductas adoptadas por los tribunales atenienses en el siglo $\mathrm{V}$ para resolver las demandas. La ciudadanía se extendió sólo a los hombres adultos libres nacidos en la ciudad en familias atenienses determinando que los niños, mujeres, extranjeros y esclavos fueron excluidos automáticamente. Se observa que los tribunales eran exclusivos de los ciudadanos atenienses. Del mismo modo, la regla eran las piezas trágicas: poetas y actores eran ciudadanos atenienses.

Varios elementos empleados en el concurso de tragedia sornen los procedimientos correspondientes en los tribunales. Helio, el principal tribunal ateniense, al igual que 
en las licitaciones, estaba compuesto por diez ciudadanos de Atenas, con un mandato anual, en un procedimiento dirigido por la asamblea y preparado para el juicio por uno de los arqueros. (FINLEY,1991)

Los juicios fueron públicos y se llevaron a cabo en un espacio abierto con presentaciones orales de ambas partes, sin abogados ni fiscales y la decisión estuvo a cargo de los ciudadanos presentes. (LOPES, 2000)

Cuando las instituciones políticas atenienses comenzaron a centralizar discusiones y temas clave relacionados con el futuro del plyólis, los ciudadanos comenzaron a preocuparse por la aristocracia, los ciudadanos ricos que podían asistir a las entidades a diario sin perjuicio de su remuneración. Para universalizar la participación del pueblo, Atenas tomó medidas como la mistoforia, que era similar al thé-ricon: el trabajo diario se pagaba a los ciudadanos para asistir a las sesiones de los organismos públicos.

Controlado por la ciudad y ejercido en lugares públicos (SEGAL, 1994). Ambos fueron preparados por magistrados de pólis, carecían de empate para componer el jurado, eran exclusivos para los ciudadanos, además del pago por la asistencia a las clases menos favorecidas, según lo determinado por Vernant y Vidal-Naquet (1999).

En el concepto de Barthes (1990), el propósito de la agonía es mediar los conflictos imparcialmente. A través de la tragedia, la propia ciudad se pregunta sobre los valores cívicos y anticívicos. (VERNANT E VIDAL-NAQUET, 1999)

Del mismo modo, la tragedia discute los dilemas que rodean la deliberación, según De Giorgi (2006). Tales dilemas se presentan al público y se resuelven en el escenario, mientras que la ciudad se enfrenta a deliberaciones en todo momento. La tragedia ofrece una pregunta sobre su propia identidad, frente a las luchas, los pasos y los lazos. El autor añade: "Los mitos presentados en la tragedia no reflejan ya los valores tradicionales de una época remota, idealizada. Por el contrario, se convierten en el campo de batalla de las luchas internas de la ciudad" (SEGAL, 1994, p. 195). 
Cabe señalar que en el corazón de la trama gira en torno a la deliberación. Filósofos como Goethe, Hegel y Lacan rescataron el desacuerdo de la duda. (ROSENFIELD, 2006). El examen de la obra abarca varios dilemas tales como: la rivalidad entre la ley de los dioses, y la ley de los hombres, apoyada por la criontea; la separación entre la civilización y la naturaleza; conflicto político, para evitar la continuación del reino de la dinastía de cadmeus. (ALMEIDA, 1997). Esta pieza presenta un momento de transformación de la propia religiosidad griega y de la reminiscencia de las narrativas mitológicas, favoreciendo a un gobierno basado en criterios y lógicas humanas.

Emplea narrativas míticas como herramienta para exteriorizar cuestiones esenciales de la política y el derecho. Las entidades primarias de plyólis democrático, según Rosenfield (2006).

La enseñanza de la ley está llena de hábitos y prosáceas, como novatadas, seguimiento, simulación del tribunal del jurado, entre otros. El límite entre la ley y el teatro está en la puesta en escena. Mientras que el teatro expone asuntos de derecho, centrados principalmente en los derechos humanos, las técnicas de las artes escénicas son herramientas pedagógicas para ayudar en la ingeniosidad del futuro grado de derecho.

En el ámbito del derecho penal, es cuando el soltero más reconoce el teatro, porque existe la simulación de juicios como los Juzgados del Jurado, para ejercer las técnicas de retorico jurídico, que abarca el oratorio, la entonación, la expresión facial y el movimiento en el espacio, que se asemejan a las técnicas de escenificación teatral.

El guión escrito por el actor Thiago Scalia en conjunto con el juez Henrique Macedo de Oliveira en 2002 se refiere a la época dictatorial comandada por Getúlio Vargas entre 1930 y 1945. La obra trató de centrarse en las violaciones de los derechos humanos.

Presidida por Katia Bizzinoto en 2014, se originó la Comisión de Cultura, actriz y directora de teatro, con el objetivo de ampliar los esfuerzos para establecer los derechos culturales entre los derechos fundamentales brasileños, a través de las 
siguientes directrices: contribuir a formar la ciudadanía cultural; promover actividades centradas en temas culturales; cooperar e influir en los proyectos de leyes con fines culturales y permitir intercambios entre el arte y la ley.

En Río de Janeiro, la institución educativa federal, a través de incentivos y asociaciones, cuenta con el programa Jurisdrama que tiene como objetivo sensibilizar y defender los derechos individuales y colectivos, una acción que, a través de cursos teatrales y representaciones, abarca la reflexión cuestiones jurídicas, sociales y económicas, cumpliendo con los requisitos de la extensión universitaria, basada en la docencia y la investigación.

\section{CONCLUSIÓN}

La ley y el teatro han estado en paralelo desde el siglo $\mathrm{V}$, cuando los homenajes al Dios Dionisio, dios de la alegría, la fertilidad y la ocultación fueron alabados con cánticos y puestas en escena. Tales representaciones transaparecieron el carácter de juicio empleado en los tribunales a través de sus historias, permitiendo al pueblo expresar su opinión sobre los asuntos comunitarios.

Había concursos para la elección de grupos que se presentarían en las celebraciones, así como el consejo que juzgaría una cierta demanda. Entre otras características, el teatro representaba el carácter social de ciertas situaciones que analizaban las leyes como justas o injustas y observando los derechos humanos. Actualmente, la enseñanza de algunas técnicas de las artes escénicas se introduce en una institución de educación superior aumentando, por lo que la experiencia del estudiante en su futura profesión permitiendo su desempeño en simulaciones del tribunal del jurado, por ejemplo, además de otras acciones que, a través del teatro buscan esclarecer temas legales, cubriendo el análisis, está la película "The Breakdown of Time", una película que retrata la realidad de muchos cargos públicos.

La crisis a la que se enfrenta el Estado y la credibilidad de quienes gestionan diversas organizaciones públicas requerían una reconstrucción interna para garantizar la 
propiedad de los contratos, además de ayudar a la coordinación económica en el mercado y reducir las desigualdades Social.

A partir de aquí, se analizaron entidades públicas, como un enfoque en las fundaciones y se procuraron examinar el Plan de Reforma del Estado, establecido en 1995. La Dirección Pública Brasileña ha experimentado importantes transformaciones en la última década en busca de una mayor eficacia de los servicios públicos. El enfoque del plan de reforma tiene como objetivo hacer que la máquina estatal sea más rápida, flexible y lista para satisfacer las necesidades sociales con un desafío gerencial. La función principal de este plan es presentar principios básicos para que los objetivos de la ampliación de la gobernanza del Estado restrinjan la acción estatal a aquellas funciones que son su propio traslado de la Unión a las actividades locales de los municipios, y parcialmente transferencia de la Unión a los Estados actividades regionales pueden establecerse plenamente.

La reforma del sector público en busca de calidad en la prestación de servicios propuso la descentralización de algunas organizaciones públicas y para implementar esta desconcentración, se necesitaban cambios en la ejecución de las actividades realizadas por los servidores Público. Entre las directrices que guiaron los propósitos determinados por la reforma se encuentra la reorganización de las entidades públicas y un cambio en las normas. Esta propuesta busca redefinir las omisiones y acciones del Estado y lograr cambios significativos en la gestión de las entidades públicas, según Silva y Fadul (2010).

La crisis a la que se enfrenta el Estado y la credibilidad de quienes gestionan diversas organizaciones públicas requerían una reconstrucción interna para garantizar la propiedad de los contratos, además de ayudar a la coordinación económica en el mercado y reducir las desigualdades Social. La globalización ha hecho pertinente redefinir los servicios públicos. En la incorporación global de mercados y modos productivos, los Estados tenían como uno de sus objetivos básicos salvaguardar sus economías de competencia internacional. Después del proceso de globalización, el Estado no pudo mantener esta postura, sino adoptar un sistema económico interno fuerte que lo haga competitivo internacionalmente. 
Primera reforma administrativa, basada en el mérito profesional. La gestión pública burocrática se estableció para reemplazar la gestión patrimonial, que caracterizó las monarquías absolutas, que no diferenciaban el límite. En este modelo de administración, el estado era propiedad del rey, así como el nepotismo y la corrupción era común.

Este tipo de gestión es antagónica, es imperativo que el capitalismo separe al Estado y el mercado y la democracia sólo existe cuando la sociedad civil se diferencia del Estado y, al mismo tiempo, lo controla. Era necesario desarrollar una forma administrativa imparcial, en este contexto surge a la gestión burocrática moderna.

Poco a poco, los cimientos de la nueva administración pública estaban diseñando las bases para la descentralización política, con la transferencia de recursos y prerrogativas a áreas políticas regionales y locales; descentralización administrativa, mediante la asignación de autoridad a los gestores públicos transformados en gestores autónomos; entidades con jerarquías más pequeñas; asumiendo una confianza limitada; y la evaluación por resultados.

La reforma instituida por el Decreto Ley 200/67 fue un esfuerzo para superar la rigidez burocrática, y puede ser considerada como la primera gestión de la gestión en Brasil. El núcleo orientado a la descentralización frente a la autonomía de la gestión indirecta. La organización, el presupuesto, la desconcentración y la evaluación de los resultados se establecieron como la base de la racionalidad administrativa.

En las bases descentralizadas, se utilizaron empleados celetistas, subordinados al sistema de contratación privada. El período favoreció la expansión de las empresas públicas. Se buscó que la flexibilidad de su gestión fuera una mayor eficacia de las prácticas económicas del Estado y el fortalecimiento del pacto político entre la burocracia tecnológica estatal, civil y militar y el sector empresarial.

Este decreto tuvo dos resultados inesperados. Al consentir la contratación de empleados sin licitación pública, facilitó el mantenimiento de prácticas patrimoniales y no realizó concursos ni planes de carrera. El centro estratégico del Estado se 
desgastó, favoreció la contratación de los altos niveles de gestión a través de las empresas estatales. El intento de reforma creado por el Decreto Ley 200 fracasó. En la década de 1970, la crisis del régimen militar agrava aún más el panorama de la gestión pública, mientras que la burocracia estatal es reconocida con el modelo autoritario en el proceso de degeneración.

La transición democrática en 1985 no presentó un horizonte favorable para las reformas de las máquinas estatales. Por el contrario, significó un regreso a las ideologías burocráticas anteriores en el ámbito administrativo, mientras que en el ámbito político, representó un regreso al populismo. Al comienzo del régimen democrático, se hizo caso omiso de la crisis fiscal y de la intervención económica, se mantuvo el sistema de intercambio de importaciones y aumentó el salario y el gasto público, factores que llevaron al fracaso del Plan de los Cruzados. Posteriormente, hubo un intento de ajuste fiscal que se vio frustrado por la falta de apoyo de la sociedad brasileña. Al mismo tiempo, la coalición política conservadora en el Congreso estableció una política populista y patrimonialista.

La Constitución de 1988 fue una consecuencia de estos movimientos contradictorios. La Carta Magna es una respuesta al populismo que se remonta a la democracia, además de realizar los cimientos de la gestión pública arcaica y burocrática con una gestión pública centralizada, jerárquica e inflexible. La sociedad y los electores presentaron una falta de capacidad para innovar, ya que no notaron los modelos descentralizados y flexibles consagrados en el Decreto-Ley 200 como resultado de una gestión eficiente del Estado.

El revés burocrático provocado por la Constitución de 1988 fue una actitud de resistencia al clientelismo que asoló el país en ese momento, pero también ratificó los privilegios corporativistas y patrimoniistas opuestos al espíritu burocrático. Estos elementos favorecieron la degradación de la gestión pública en Brasil, aunque la competencia y la honestidad de los administradores públicos brasileños son notorias.

La inestabilidad fiscal e intervencionista se originó a partir de 1987. Sólo con la hiperinflación durante el mandato de José Sarney la sociedad se dio cuenta de la 
gravedad de la crisis, al citar medidas, en la negociación de igualar la economía, la atención del gobierno de Fernando Collor ganó, en este período turbulento se produce a la apertura comercial, con Privatización. Los ajustes fiscales obtienen directrices permanentes y el país logra una amplia cancelación de la deuda pública nacional.

En el contexto de la gestión pública, las reformas han tomado un rumbo diferente. Este fracaso se debió principalmente al torpe intento de reducir la máquina estatal, exonerando a los funcionarios y cerrando órganos, sin reocuparse de la legalidad de las medidas. Hubo una reducción salarial de los servidores y la desorganización de la estructura burocrática existente, deshonrando a los servidores públicos, reconocidos por el corporativismo (protección de intereses en un grupo como si representaran los intereses de la nación).

El gobierno de Itamar, (post-impeachment), con la difícil misión, ante un escenario, de recesión, descrédito, falta de confianza en el Gobierno, (interno y externo), sufriendo las consecuencias, de una gestión ineficaz. En su primer año contestaba la capacidad técnica del equipo económico del Ministerio de Hacienda en ese momento, junto con el deseo de reequilibrar las cuentas públicas y los fideicomisos y personas del mercado. Así, comienzan las acciones basadas en estudios científicos, que discreron el origen de la carrera de los gestores públicos, especializados en Políticas Públicas y Gestión Gubernamental.

El servicio público se ha vuelto más ineficaz, más costoso y autónomo. La división fue preparada no sólo por el modelo patrimonialista, sino también por la imposición de un sistema jurídico unificado, con la exoneración de celetistas y la afirmación constitucional de un modelo de estabilidad rígido, donde la evaluación de rendimiento de los servidores Esta estabilidad del funcionalismo público es un aspecto inherente a la gestión burocrática y se estableció con el fin de proteger a los servidores y al propio Estado. En Brasil, durante el período imperial, cuando un gobierno fue depuesto, muchos funcionarios de confianza, además de otros ciudadanos comunes y corrientes perdieron sus posiciones. 
La estabilidad, sin embargo, tiene un costo, impidiendo la adaptación del marco de trabajo del servidor a las verdaderas necesidades del servicio. Por otra parte, imposibilite la introducción de un régimen eficaz de gestión pública basado en un modelo de incentivos y castigos.

Se abordaron tres factores relevantes que influyen en la degradación de la imagen de las instituciones públicas, como la corrupción, la cultura brasileña y la ineficiencia gerenciales.

La educación brasileña siempre ha sido precaria, ya que se dirige al diploma y no al conocimiento. La cultura de los indios y los negros era restrictiva y no se les permitía aprender, esta divergencia entre la abstracción política avanzada y el retraso del medio ambiente, demostró el punto de desorientación cultural inherente a los pueblos con antecedentes coloniales.

A mediados del siglo XXI, Brasil tiene una tasa de analfabetismo del $7 \%$ entre las personas de 15 años o más según datos del IBGE (OLIVEIRA, 2018). Un índice todavía lejos de los presentados por los países desarrollados y algunos en desarrollo. El panorama de la deseducación de la población brasileña impide una mayor interferencia en las deliberaciones del sistema, sin embargo la sociedad se despierta gradualmente, tal vez por el advenimiento de Internet o por el cansancio ante el desequilibrio educativo.

La corrupción es uno de los temas más comentados hoy en día y es considerado por los eruditos como una cuestión moral y ética. Bezerra (1995) conceptualiza la corrupción como un "fenómeno de naturaleza estructural, arraigado en nuestra formación social, nuestros hábitos y costumbres". Según dicho autor, para resolver el problema, deben establecerse normas morales más estrictas y éticas. Desde un punto de vista sociológico, es imperativo examinar que, beneficiándose de los principios morales como base para este fenómeno, se abandonan los debates sobre las condiciones sociales que ayudan a la subsistencia y renovación de la corrupción en el país. (BEZERRA, 1995). Para cambiar este panel, la acción de toda la sociedad en la confrontación contra la corrupción es muy relevante. El esfuerzo social constante y la 
condena de los corruptores pueden emplear cambios importantes para reducir o incluso erradicar la corrupción en el país (STUKART, 1988).

En cuanto a la ineficiencia gerenciales, vale la pena mencionar que los métodos de gestión deben establecer valores importantes como la productividad de calidad y la responsabilidad. Como se ha visto anteriormente, la crisis burocrática de la gestión pública brasileña se originó en el régimen militar, frente al patrimonialismo que permitió el reclutamiento de gerentes a través de empresas estatales. Hay divergencias entre el empleo por parte de la máquina pública del estado del sistema de administración híbrida, es decir, entidades que prestan servicios con el apoyo de la recaudación de impuestos, pero también con patrocinio privado. A esto se suma la burocracia que involucra a las organizaciones públicas. La falta de inversiones en tecnología afecta al aumento de la velocidad en los servicios públicos, ya que los procedimientos en línea tardan un $74 \%$ menos que los presenciales en completarse y generar un menor costo.

Una breve analogía entre el teatro, sus personajes e instituciones públicas. Las organizaciones públicas son partes sin un script definido, ya que las directivas establecidas cambian sus operaciones. En busca del público, los actores tratan de dar lo mejor de sí mismos, pero se ven impedidos por cuestiones de infraestructura, ya que el aumento de la velocidad del funcionalismo se enfrenta a la burocracia que obstaculiza a los usuarios. Por otro lado, el director se encuentra atar la mano, ya que debe inclinarse ante los patrocinadores. La ineficiencia gerenciales es también una consecuencia de las políticas instituydas por el Estado y de todos los procedimientos a los que se enfrenta el jefe de una institución pública para lograr mejores condiciones de trabajo o ingresos.

Lo más importante es que esta pieza se mantenga en exhibición, con un guión definido, buenos y eficientes actores, con patrocinio constante y espectadores satisfechos, independientemente del tiempo. 


\section{REFERENCIAS}

ADMIN. Fundações Públicas e Privadas: Equiparação: Inconstitucionalidade. 2008. Disponível em:< http://www.altosestudos.com.br/?p=41230>. Acesso em: 06 dez 2019.

ALMEIDA, G; VIEIRA, T. Três tragédias gregas: Antígona, Prometeu prisioneiro e Ájax. São Paulo: Perspectiva. 1997

ANDRADE, Regis de Castro. Estrutura e organização do Poder Executivo frente à opção pelo sistema de governo: Estrutura da Administração Pública e gestão de recursos humanos em quatro países parlamentaristas da Europa: França, GrãBretanha, Espanha e Itália. São Paulo: Cedec, 1993.

ANDRADE, Regis de Castro; JACCOUD, L. Estrutura e organização do poder Executivo. Brasília: ENAP/SAF, vol. I. 1993

ARAGÃO, Cecilia Vescovi de. Burocracia, eficiência e modelos de gestão pública: um ensaio. $1997 . \quad$ Disponível em:< http://www.bresserpereira.org.br/Documents/MARE/Terceiros-Papers/97Arag\%C3\%A3o,CVescovide48(3).pdf>. Acesso em: 06 dez 2019.

BARTHES, R. O teatro grego. In. O óbvio e o obtuso - ensaios críticos III. Trad. Léa Novaes. Rio de Janeiro: Nova Fronteira. 1990

BEZERRA, Marcos Otávio. Corrupção: um estudo sobre poder público e relações pessoais no Brasil. Rio de Janeiro: Relume Dumará, 1995.

BID (Banco Interamericano de Desenvolvimento) e OCDE (Organização para a Cooperação e Desenvolvimento Econômico). 2016. Government at a Glance 2017. París: OCDE. Disponível em: http://dx.doi.org/10.1787/gov_ glance-2017-en.. Acesso em: 06 dez 2019

BOBBIO, Norberto. A era dos direitos. Rio de Janeiro: Campus, 1992. 
BRASIL. Constituição da República Federativa do Brasil, 1988. Disponível em: <https://www2.senado.leg.br/bdst/bitstream/handle/id/518231/CF88_Livro_EC91_20 16.pdf >. Acesso em: 06 dez 2019.

BRASIL.

Decreto

lei

200/67.

Disponível

em:

$<$ https://presrepublica.jusbrasil.com.br/legislacao/104099/decreto-lei-200-67>.

Acesso em: 06 dez 2019.

BRASIL. Plano Diretor da Reforma do Aparelho do Estado. Brasília: 1995. Disponível em:< $\quad$ http://www.biblioteca.presidencia.gov.br/publicacoesoficiais/catalogo/fhc/plano-diretor-da-reforma-do-aparelho-do-estado-1995.pdf >. Acesso em: 06 dez 2019.

BRASIL. Burocracia e Politicas Públicas no Brasil: interseções analíticas. Brasília, 2018.

Disponível

em:

<http://repositorio.enap.gov.br/bitstream/1/3247/1/livro_Burocracia\%20e\%20pol\%C3 \%ADticas\%20p\%C3\%BAblicas\%20no\%20Brasil\%20-

\%20interse\%C3\%A7\%C3\%B5es\%20anal\%C3\%ADticas.pdf>. Acesso em: $06 \mathrm{dez}$ 2019.

BRASIL. Jurisdrama. Disponível em:<http://www.jurisdrama.ufrj.br/>. Acesso em: 06 dez 2019.

CALEGARI, Luiza. Percepção de corrupção no Brasil é a pior em cinco anos. Revista Exame. Disponível em: < https://exame.abril.com.br/brasil/percepcao-decorrupcao-no-brasil-e-a-pior-em-cinco-anos/> Acesso em 06 dez. 2018.

CARVALHO FILHO, José dos Santos. Manual de Direito Administrativo. Rio de Janeiro: Lumen Juris $21^{\circ} \mathrm{ed} .2009$

CARVALHO, Virginia Donizete de; OLIVEIRA, Thais Aluxe de; SILVA, Daniele Cristhiane da. Valores organizacionais em instituições públicas brasileiras: percepções dos servidores em diferentes posições hierárquicas e tipos de 
entidade da administração indireta. 2013. Disponível em:< http://www.scielo.br/pdf/ram/v14n5/04.pdf >. Acesso em: 06 dez 2019.

DE GIORGI, R. Direito, tempo e memória. Trad. Guilherme Leite Gonçalves. São Paulo: Quartier Latin, 2006.

DINIZ, Gustavo Saad. Direito das Fundações Privadas - Teoria Geral e Exercício das Atividades Econômicas. 2. ed. Porto Alegre: Síntese, 2003.

FERLIE, Ewan; ASBURNER, Lynn; FITZGERALD, Louise; PETTINGREW, Andrew. A nova administração pública em ação. Trad. Sara Rejane de Freitas Oliveira. Brasília: ENAP, 1999.

FERRARI, Hamilton. Correio Braziliense. Burocracia: setor público leva 5,5 horas para realizar único procedimento 2018. Disponível em: $<$ https://www.correiobraziliense.com.br/app/noticia/economia/2018/06/11/internas_ec onomia,687669/burocracia-setor-publico-leva-5-5-horas-para-realizar-unicoprocedime.shtml>. Acesso em: $06 \mathrm{dez} 2019$.

FINLEY, M.I. Aspectos da Antiguidade. Trad. Marcelo Cipolla. São Paulo: Martins Fontes, 1991.

JUSTEN FILHO, Marçal. Curso de Direito Administrativo. São Paulo: Saraiva, 2008

LAHÓZ, André. Liberem o Crescimento. Revista EXAME, São Paulo, № 23, ano 37, ed. 805, 2003.

LIMA, Luís. Tempo perdido com burocracia custa mais ao Brasil que impostos, diz diretora do Banco Mundial. 2017. Disponível em: $<$ https://epoca.globo.com/economia/noticia/2017/09/custo-do-tempo-pesa-mais-queo-financeiro-diz-diretora-do-banco-mundial-sobre-burocracia-brasileira.html>. Acesso em: 06 dez 2019. 
LOPES, J.R. Lima 0 direito na história: lições introdutórias. São Paulo: Max Limonad. 2000

MARINI, Caio. Gestão Pública: O Debate Contemporâneo. Cadernos da Fundação Luís Eduardo Magalhães. № 07. Salvador: Fundação Luís Eduardo Magalhães, 2003.

MAZILLI, Johnny. Revista Planeta. O que é que a Coreia tem? 2011. Disponível em: $<$ https://www.revistaplaneta.com.br/o-que-e-que-coreia-tem/>. Acesso em: $06 \mathrm{dez}$ 2019.

MENDONÇA, Saulo Bichara. Quimera da eficiência no serviço público desestruturado. $2017 . \quad$ Disponível em:< https://professorsaulo.jusbrasil.com.br/artigos/457823003/quimera-da-eficiencia-noservico-publico-desestruturado?ref=topic_feed >. Acesso em: 06 dez 2019.

MONTEIRO, Carolina. Correio de Uberlândia. Teatro ajuda futuros juristas na formação e cumpre papel social. 2018. Disponível em: $<$ http://www.correiodeuberlandia.com.br/entretenimento/teatro-ajuda-futuros-juristasna-formacao-e-cumpre-papel-social/>. Acesso em: 06 dez 2019.

MOTTA, P. R. A modernização da administração pública brasileira nos últimos 40 anos. Revista de Administração Pública, v. 41, n. esp., p. 87-96, 2007.

MOTTA, F. C. P.; VASCONCELOS, I. F. G. Teoria geral da administração. 3. ed. São Paulo: Thomson Learning, 2006.

OLIVEIRA. Nielmar de. Agência Brasil. IBGE: taxa de analfabetismo cai $\mathbf{0 , 2}$ ponto percentual em 2017. 2018. Disponível em: <http://agenciabrasil.ebc.com.br/economia/noticia/2018-05/ibge-taxa-deanalfabetismo-no-pais-cai-02-ponto-percentual-em-2017>. Acesso em: 06 dez 2019.

OSBORNE, David; GAEBLER, Ted. Reinventando o Governo. Tradução Sérgio Bath e Ewandro Magalhães Júnior. Brasília: MH Comunicação, 1994. 
PINHO, Antônio. Evolução do Estado Moderno. In: MACHADO, Geraldo et al. Gestão Pública: Desafios e Perspectivas. Cadernos da Fundação Luís Eduardo Magalhães. n 01. Salvador: Fundação Luís Eduardo Magalhães, 2001.

PEREIRA, Luiz Carlos Bresser. Da administração Pública burocrática à gerencial. Revista do Serviço Público: ENAP, ano 47, v. 120, 1996.

PEREIRA, Luiz Carlos; SPINK, P.K (Orgs.) Reforma do Estado e Administração Pública Gerencial. Ed. Rio de Janeiro: Fundação Getúlio Vargas, 1998.

PEREIRA, Luiz Carlos; SPINK, P. Reforma do Estado e Administração Pública Gerencial. 3. Ed. Rio de Janeiro: Fundação Getúlio Vargas, 1999.

PORTAL EDUCAÇÃO. A História do Teatro no Brasil e no mundo. Disponível em: $<$ https://www.portaleducacao.com.br/conteudo/artigos/direito/historia-do-teatro-nobrasil-e-no-mundo/50069>. Acesso em: 06 dez 2019.

RAYOL, Paulo André Araújo. Fundações públicas e privadas. 2017. Disponível em: $<$ https://jus.com.br/artigos/59258/fundacoes-publicas-e-privadas >. Acesso em: 06 dez 2019.

REALE, Miguel. Filosofia do Direito. 20. Ed. São Paulo: Saraiva. 2009

RIZZO, Sérgio. Crítica: A Repartição do tempo. 2018. Disponível em: <https://oglobo.globo.com/rioshow/critica-reparticao-do-tempo22349905\#ixzz5PfxLOq4X>. Acesso em: 06 dez 2019.

ROESLER, Átila da Rold Justificando. As instituições Públicas não estão funcionando. Disponível em: < http://justificando.cartacapital.com.br/2017/12/13/asinstituicoes-publicas-nao-estao-funcionando/ > Acesso em: $06 \mathrm{dez} 2019$.

ROSENFIELD, K.H. Introdução, Comentários e notas. In: Sófocles. Antígona. Trad. Lawrence Flores Pereira. Rio de Janeiro: Topbooks. 2006

SCHAUN, Raimundo. Comunicação, Poder e Democracia. São Paulo: IPCJE, 1986. 
SEGAL, C. O ouvinte e o espectador. In: Vernant, J-P. (org.). O homem grego. Trad. Maria Jorge Vilar de Figueiredo. Lisboa: Editorial Presença. 1994

SENADO. Jus Brasil. Ana Amélia defende fortalecimento de instituições públicas. 2013. Disponível em:< https://senado.jusbrasil.com.br/noticias/100486565/anaamelia-defende-fortalecimento-de-instituicoes-publicas>. Acesso em: 06 dez 2019.

SILVA, Camila Garcia da. Revista Liberdades. 0 caso dos Irmãos Naves. Disponível em:

$<$ http://www.revistaliberdades.org.br/site/outrasEdicoes/outrasEdicoesExibir.php?rco n_id=58>. Acesso em: $06 \mathrm{dez} 2019$.

SILVA, L. P.; FADUL. A produção científica sobre cultura organizacional em organizações públicas no período de 1997 a 2007: um convite à reflexão. Revista de Administração Contemporânea, v. 14, n. 4, art. 5, p. 651-669, 2010.

SODRÉ, Nelson W. Síntese de história da cultura brasileira. $18^{\circ}$ ed. Rio de Janeiro: Bertrand Brasil, 1996.

STUKART, Herbert L. Ética e Corrupção nas Empresas com Enfoque sobre Compras. Salvador: ABAM - Associação Brasileira de Administração de Material. Caderno de Administração de Materiais. № 05, 1988.

SUPREMO TRIBUNAL FEDERAL. ADI 191-4. Relatora Ministra Carmen Lúcia. Disponível< file://C:/Users/CLIENTE/Downloads/STF\%20\%20ADI\%20n\%C2\%BA\%20191\%20RS\%20(2).pdf > Acesso em.: 06 dez 2019.

TEIXEIRA, Glória. Direito e Estudos Teatrais. In: Teatro do Mundo. Universidade do Porto. 2018. Disponível em: <http://ler.letras.up.pt/uploads/ficheiros/10182.pdf> Acesso em: 06 dez 2019.

VERNANT, J-P e VIDAL-NAQUET, P. Mito e tragédia na Grécia antiga I e II. Vv. trad. São Paulo: Perspectiva. 1999

Enviado: Noviembre, 2019. 
Aprobado: Enero de 2020. 